\title{
Skating to Where the Puck is Going to Be
}

Steven Warren, Vice Chancellor for Research and Graduate Studies, University of Kansas

1 A good hockey player plays to where the puck is. A great hockey player plays to where the puck is going to be." So goes a famous and often quoted observation attributed to the great professional hockey player Wayne Gretsky. Whether this is actually a good recommendation for a hockey player is beside the point. The statement captures the challenge that is especially pertinent for the legions of professionals trying to figure out where the ongoing revolution in informational technologies is going so that they can "be there when it arrives" instead of lagging behind.

The purpose of this essay is to offer my perspective, as a Chief Research Officer at a Midwestern university, on a few of the challenges we face as we skate forward into the future. My essay is divided into three sections. First, what is it that we really want from information technology? Second, what are a few of the big picture issues generated by the IT revolution and their local relevance? Finally, I offer a few closing thoughts.

What do we want? If you are on the business side of the IT revolution, you want to know: "What does the consumer want?" That's where the consumer market is and that is what big businesses (e.g. Microsoft, Apple) are going to try to satisfy. There are lots of things we'd all like to have. These include transparency, convergence of technologies, simplicity (meaning that we want the complexity to be hidden by straightforward and intuitive interfaces), and of course we want safety and security from hackers, thieves, etc. Yet as important as these needs are, two even more basic elements top them all. These are SPEED and
POWER. An obvious example of speed and power at a basic consumer level is the progression from the first Iphone to Iphone5. The first Iphone was amazing. But the Iphone5 (as was the case with Iphone 2, 3, and 4) beats it in terms of processing speed and the wide range of things it can do with this speed - that is its power.

Now translate the same concepts into what scientists want. First they want to assume all the same basic stuff meaning they want convergence, transparency, simplicity and safety/security. But what they REALLY crave is speed and power. In our case (speaking with my scientist hat on now), we want the speed and power to communicate, teach, and learn from anywhere in the world at any time, with ease. We want to have the power and speed to analyze remarkably complex problems. These include the ability to study the most complex known object in the universe (the human brain), the basis of life in all its forms, our planet and how it operates and behaves, and of course the universe itself. 
Yes, we are indeed an ambitious and pretentious species - one with an almost unquenchable thirst for SPEED and POWER. Furthermore we have become totally spoiled over the past 40 years as a result of Moore's law and the remarkable skills of a small group of computer scientists and engineers who exploited this so called law. Moore's law observes: "...over the history of computing hardware, the number of transistors on integrated circuits doubles approximately every two years" (Wikipedia). What this doubling has enabled is the remarkable virtually exponential gains in SPEED and POWER every two years. Exponential growth is so fast that most of us struggle to even conceive of what it actually means, let alone how to keep up with it. But it has enabled extraordinary breakthroughs in science, education, entertainment, transportation, and on and on. It is literally transforming our world in countless ways.

However, we may be nearing the end of this incredible ride. Various individuals and groups predict that we are very close to the end of Moore's law, or at least to it slowing down. Some even think that the end of Moore's law will have huge negative impact on economic development with devastating consequences. Others believe it will be little more than a speed bump in the road and that breakthroughs in other areas (e.g. nanotechnology) will keep pushing us rapidly ahead. Actually, if things did slow down a bit, that will have its positive effects too - such as allowing as to consolidate all of our technological breakthroughs and catch up just a bit.
Skating to Where the Puck is Going in an Era of Radical Change

Many of the real impacts of the remarkable changes in information technologies are just emerging on the horizon. These changes are already having a big impact on the higher education enterprise in general and a tsunami of disruptive change appears to be roaring right at us. So how does one manage a big, complicated university research enterprise in this environment? What are some of the changes that are already roaring through the Ivy Tower? There are lots of examples of these. I'll share just four unique examples of the changes underway in the world of research.

1. The infrastructure of research administration. One of my goals is to transform the research administration experience for scholars at the University of Kansas by creating a fully integrated electronic research administration system. Most of our system is already electronic of course. But it is not integrated in any way that allows people to efficiently and effectively manage it. I want to put the Investigator at the head of the line - they are the reason for research administration, they are the customers. They are the ones that need a straightforward easy way to use systems that will make the administration of their research easier, instead of more complicated.

Here is what that might look like: I, Mr. Researcher, flip open my laptop anyplace in the world, put in my password, and open my personal faculty research portal. Everything I need to effectively manage my 
grants and projects is right there. I can check the financial balance of my grants, look at projections given my present rate of spending, update and submit a request to the Institutional Review Board, work on a new proposal, submit and monitor a travel request, and on and on. This sounds reasonable enough - we just need to get these systems to converge and all start talking the right language.

In fact, it's been a big challenge. We haven't solved it yet, but we are on the path. When we started down this path several years ago, it became obvious to me that we needed someone really comfortable in this integrated electronic world. And so, I now have a 28 year old Assistant Vice Chancellor overseeing our entire research administration system. He is capable of leading this change while those with much deeper research administration experience may struggle because they lack his technological sophistication and comfort.

2. Avoid the front of the line. In the rapidly changing world we live in, the most exciting place to be is of course on the front end of innovation. It can also easily be the most expensive, complicated, and disappointing place to be. Why? First, often at the front of the line you pay the highest price for something because market forces have not yet taken over (note: it can sometimes be cheaper too because companies are selling low in order to break into a market). Second, lots of things don't work very well right out of the box.
Their performance improves with time and experience, because companies know they must make those improvements or ultimately the customers will walk away. Third, sometimes new innovations simply fail when they go to a larger scale. We had this exact experience at $\mathrm{KU}$ when we signed up with a company that was in the process of creating a "PI portal" just like I described above. It didn't end up costing us very much money, but it did cost us a lot of time. Ultimately we will achieve our goal, but the wasted time and effort associated with being an early adopter was a sobering experience. Bottom line, letting others serve as the early adopters may mean that you get a better, more reliable and cheaper product in the end.

3. The changing nature of research collaborations. In my experience, the hyper competitive world of research in combination with the hyper connected world of we live in, has resulted in profound changes in collaboration amongst scholars. It is still the case that we like to collaborate with colleagues who work near us all other things being equal. This kind of collaboration can be relatively easy and are sometimes especially creative. But we generally don't collaborate with people just because we like them or they are nearby. Instead we most often collaborate because we need to in order to be successful, and often because it's the only way to bring a sufficiently wide range of 
skills to bear on some complicated research problem we face.

A fundamental outcome of the IT revolution has been the change it has made in terms of how easy it is to collaborate with anyone almost anywhere. We easily collaborate with people all over the world...people that we may rarely see (expect perhaps on computer screen). We may still want to have some actual physical contact with these collaborators to build a sufficient level of trust. But that's it. Our technologies allow us to solve virtually all of the analytic and technical problems that in the past would have stymied these types of collaborative efforts, or simply made them too expensive and complicated to do. As a result, my experience has been that scientists will seek out whoever they need to solve the challenges they face, often without regard to location. This has contributed to the explosion of scientific knowledge over the past couple of decades.

4. Scientific Fraud is becoming much easier to catch. With all the reports of scientific fraud over the past decade, it would be easy to assume that many scientists have lost their moral compass and are trying to cheat their way to fame and fortune. It is true that the pressure to be successful, to stay funded, may have increased and thus contributed to the increase in fraudulent data. But maybe it was there all along and was just too hard to catch. We will probably never know, but we do know that it is getting much easier to catch certain types of scientific misconduct due to breakthrough technologies that themselves are just another side effect of the IT revolution.

The biggest change is in our ability to detect plagiarism. Scientific journals can now subscribe to services that will scan each submission they receive and compare it to countless related papers that have been published all over the world, in a search to detect instances of plagiarism. Some people even make this a kind of hobby - finding papers in the literature that contain a significant amount of plagiarized material and then reporting the alleged perpetrator. Because of this, I anticipate that plagiarism will all but disappear as a scientific concern in the near future.

And the most serious type of scientific misconduct - publishing false or fabricated data - may not be far behind, as powerful techniques are perfected that can detect highly unlikely findings that at the minimum, need external replication to determine their accuracy and validity. These kinds of innovative tools have recently been applied to some areas of social science where the crucial tool of independent replication has rarely been used in the past to identify questionable findings that need to be further tested. Will scientific fraud eventually vanish in our hyperconnected world? Probably not completely, but the quality and reliability of science overall is already being significantly improved by breakthrough tools that owe their existence to the IT revolution. 


\section{Final Thoughts}

We live in truly remarkable times. The pace of technological and scientific innovation is staggering. The foundation for much of this is the ongoing tsunami generated by the information technology revolution. This tsunami is washing over higher education and may ultimately radically transform many aspects of what stands as perhaps the most enduring institution of the past five hundred years. Universities in fact are the origin of much of this disruptive, creative destruction that is rolling across virtually every corner of the world. But being part of the source of this revolution does not in any way inoculate us from its transformative effects. Consequently some of the really big questions remain to be answered. For example, will the basic model of research universities survive the exponential changes in information technologies? That and so much more remains to be determined. In the meantime, Wayne Gretsky's famous quote remains mostly an aspirational goal. The puck is speeding ahead of us exponentially, and spreading out in many different directions. Nevertheless, we must keep trying to skate to where we think it is going. 